\title{
EDITORIAL
}

\section{CIRCADIAN RHYTHMS IN MAN}

THE ways of mice and men in relation to biological rhythms were studied extensively by Halberg, Halberg, Barnum and Bittner (1959), whence was coined the word 'circadian' to denote those that have a periodicity of about twenty-four hours-circa diem. The term ' nychthemeral', as pertaining to a period of twenty-four hours consisting of a day and a night, is used by French physiologists but has not proved as acceptable as 'circadian' in English-speaking circles, while the word ' diurnal' is falling into disuse since it is more properly to be regarded as 'not nocturnal' in its descriptive powers. It is perhaps of value to the reader to emphasize that 'circadian' describes periodicities which may be short of or slightly in excess of twenty-four hours exactly, while 'infradian' and 'supradian' are reserved for those that are much shorter or much longer.

Claude Bernard's concept of la fixeté du milieu intérieur holds sway no longer and we are urged by Halberg and many others to envisage un milieu whose components are constantly changing in a rhythmic fashion which is predominantly circadian in periodicity (Mills, 1966). The existence of biological rhythms has been recognised much longer in plants and animals than in man, both the short-lived or circadian and the lengthy or seasonal such as flowering and breeding. In man, seasonal rhythms in physiological function are no longer easily detectable, whereas circadian patterns have recently been described and measured in nearly every physiological system.

Biological functions having a rhythmic oscillation are termed endogenous or freerunning when they are independent of any external influence, exogenous when entirely dependent on an external rhythm, say, of habit or environment, or they may result from an interaction between the two. Thus Mills (1964) is of the opinion that Lewis and Lobban were probably observing an endogenous rhythm when they reported the persistence of a 24-hour renal excretory rhythm in subjects living on artificial 21, 22 and 27hour days in Spitzbergen. However, Sharp (1962) has shown that urinary flow and specific gravity might be of the exogenous variety when, using a more drastic method in which his subjects in Spitzbergen reversed completely their sleep/wakefulness habits, he demonstrated that a reversal of these parameters took place on the sixth day. Unfortunately he did not investigate the electrolyte content of the samples. That the renal excretory rhythm may result from interaction between the endogenous and exogenous types of rhythm is suggested in the results of Adam, Lobban and Tredre (1964) obtained from a group of 18 Indian Army personnel flown from Lucknow to England. After an initial disorganization of pattern of the urinary constituents, it was still possible to demonstrate the influence of Lucknow time on the potassium excretion on the 63rd day after arrival in England in seven of the subjects.

Mills (1966) has criticised attitudes that stifle further research, and maintains that the practical importance of these rhythms can hardly be doubted when evidence is available to show that mortality from a given dose of toxin or chemical agent may be many times greater at one time of day than at another, as also may post-surgical mortality. McGirr (1968) is equally forthright in stating that, as physicians, we are not so naive as to believe that the administration of a drug is equally effective, or ineffective, at every hour of the day or night. The response to a constant dose of a drug varies in a circadian manner-but this fact is either not appreciated or not applied in hospital and general practice. There are parameters in the psychological and physiological fields having 
components which show variations with a circadian periodicity, and the effects of their disruption by altered living habits are becoming better documented in certain population groups. Numbered amongst these may be workers having to alternate night duty with day duty in industry and the medical and other services, business executives, politicians, aircrew and service-men who have to undergo rapid movement across global time zones, and a group with particular problems, comprising underground cave dwellers, polar explorers, submariners and astronauts.

The area in which most research remains to be undertaken is perhaps in the field of rapid transport over vast (but terrestrial) distances. Adam (1967) has cited personal and derived evidence to indicate that flights involving substantial changes in clock-time result in disruption of circadian rhythms and lowered efficiency. Furthermore, the direction of the flight can be of importance-Hauty and Adam are quoted as showing that a flight in the eastward direction, which was shorter in duration and of smaller clock-change than one towards the west, caused a greater disturbance and required more days for the physiological and psychological parameters to re-establish their circadian rhythms.

\section{REFERENCES}

Adam, J. M., Lobban, M. C. and Tredre, B. E. (1964). Diurnal rhythms of renal excretion and of body temperature in Indian subjects after a sudden change of environment. J. Physiol. $177,18$.

ADAM, J. M. (1967) Military problems of air-transport and tropical service Pp. 74-80. The Effects of abnormal Physical Conditions at Work. Ed. Davies, Davies and Tyrer. Livingstone, London.

Halberg, F., Halberg, E., Barnum, C. P. and BitTner, J. J. (1959). Physiologic 24-hour periodicity in human beings and mice, the lighting regimen and daily routine. $\mathrm{Pp}$. 803-878. Photoperiodism and Related Phenomena in Plants and Animals. Ed. Withrow. Publ. No. 55, Am. Assn Advmt Sci.

McGirR, P. O. M. (1968). Circadian Rhythms in Flight. Trans Soc. Occup. Med. 18, 3.

MuLs, J. N. (1964). Circadian Rhythms during and after three months underground. J. Physiol. $174,217$. Mills, J. N. (1966) Human Circadian Rhythms. Physiol. Rev. 64, 128.

SharP, G. W. G. (1962). Persistence of the Diurnal Rhythm of flow of urine. Nature. 193, 37.

\section{INTERMITTENT REGIMES OF TUBERCULOSIS CHEMOTHERAPY}

The publication of the final reports on the studies of tuberculosis chemotherapy at the Army Chest Centre (Eade, Harrison, Large and Mackay-Dick 1968a, Eade and Mackay-Dick, 1968b), provides an opportunity for considering some general problems relating to intermittent regimes-those in which chemotherapy is administered at intervals of two days or more. When streptomycin, para-aminosalicylic acid (PAS) and isoniazid first became available, controlled clinical trials soon established their efficacy, the limitations imposed by the emergence of drug resistance if one drug only were given, and the effectiveness of combinations of two of them in sufficient dosage in delaying the emergence of drug resistance. The latter finding made it possible to continue chemotherapy long enough to cause bacteriological cure of even extensive and cavitated pulmonary tuberculosis. The Medical Research Council (1955) trials included a regime in which isoniazid was given daily with streptomycin twice weekly, which led to the emergence of a considerably higher proportion of resistant strains of bacilli than did daily administration of two effective drugs. Possibly this experience caused a temporary loss of interest in intermittent regimes.

It is evident, however, that this early unfavourable experience with the intermittent use of drugs from the beginning of treatment can not be extrapolated to apply either to the use of such regimes after an initial period of daily treatment, or to the intermittent use of drugs in high dosage throughout treatment. There is now abundant evidence that suitably planned regimes of both these sorts can be effective. 
It seems likely, a priori, that after an initial period of daily two or three-drug treatment had reduced the bacterial population, a less intensive regime might suffice to ensure continued clinical improvement and eventual bacteriological cure without permitting the emergence of resistant bacilli in more than a small minority of cases. The studies at the Army Chest Centre and British Military Hospital, Kinrara (Eade et al, 1959) have confirmed this expectation, as have several subsequent studies (Poole and Stradling, 1965). The probable changes of viable bacilli during such regimes of treatment have been mimicked in the laboratory by careful studies in experimental murine tuberculosis (Canetti, Grumbach and Grosset, 1963, Grumbach, Canetti and Grosset, 1964, Grumbach, Canetti, Grosset and Le Lirzin, 1965). After an initial period of several months' triple drug treatment, other simplified regimes-for example, continuation with isoniazid alone-may be effective in patients with initially drug-sensitive infections (International Ùnion against Tuberculosis, 1964).

A preliminary period of daily treatment has been found to increase greatly the success of imtermittent treatment with two drugs in the dosage customarily used for daily administration, but there is laboratory evidence that some combinations of two drugs given in larger than usual doses as infrequently as twice a week might be effective even from the beginning of treatment. These studies suggest that of the drugs at present available, streptomycin is the most likely to be useful in intermittent regimes, and that isoniazid is likely to be useful if it is given in a dose large enough to produce an effective blood level for more than twelve, and preferably twenty-four hours (Dickinson and Mitchison, 1966). In a clinical trial in Madras (Tuberculosis Chemotherapy Centre, Madras, 1964 and Nazareth et al, 1966) a regime of streptomycin $27 \mathrm{mg} / \mathrm{kg}$ and isoniazid $14 \mathrm{mg} / \mathrm{kg}$ (average dosage-levels) on two days a week throughout treatment proved successful. In Algiers (Chaulet, Larbaoui, Grosset and Abderrahin, 1967) a similar regime was found to be rather less successful than one in which an initial period of continuous triple drug treatment was given, but this result was probably affected by a high incidence of pre-treatment drug resistence. It is, of course, essential to the success of any regime that the bacilli should initially be sensitive to the drugs being used.

In the Army Chest Centre studies, the chief advantages of the intermittent regime were the lower incidence of toxic effects and greater comfort for the patients. In other contexts, the chief advantage of an effective treatment that can be given at intervals of several days is the possibility that it offers of complete supervision of out-patient treatment. The chief drawback to the most frequently used scheme of long-term out-patient treatment by oral PAS-isoniazid is that it depends upon the patient's conscientious and continuous co-operation. The possibility of effective treatment by supervised administration of drugs not more frequently than twice-weekly should improve the results of out-patient chemotherapy which must be the mainstay of the control of tuberculosis in developing countries. Unfortunately, unlike that of the Army's Gurkhas, the treatment of inhabitants of countries with an uncontrolled tuberculosis problem is affected by financial considerations; the cost of streptomycin is high in relation to the resources of such countries, and the search for cheaper but still effective combinations of drugs must continue. 
Eade, A. W. T., Harrison, G. K., Large, S. E., Mackay-Dick, J., Reid, L. and Riddell, R. A. (1959). Thorax. 14, 104.

Eade, A. W. T., Harrison, G. K.; Large, S. E. and Mackay-Dick, J. (1968a). J. roy. Army med. Cps. $114,24$.

EADE, A. W. T. and Mackay-Dick, J. (1968b). J. roy. Army med. Cps. 114, 73.

Grumbach, F. Canetti, G. and Grosset, J. (1964). Tubercle (Lond.). 45, 125.

Grumbach, F., Canetri, G., GrosseT, J. and Le LiRzin, M. (1965). Tubercle (Lond.). 48, 11.

INTERNATIONAL UNION AGAINST TUBERCULOSIS (1964). Bull. int: Un. Tuberc. 34, No. 2.

Medical Research CounCil (1955). Brit. med.J. 1, 345.

Nazareth, O., Devadatta, S., Evans, C., FoX, W., Janardhanam, B., Menon, N. K., Radhakrishna, S., Ramakrishnan, C. V., Stott, H., Tripathy, S. P. and Velu, S. (1966). Tobercle (Lond.). 47, 178. Poole, G. and Stradling, P. (1965). Tubercle (Lond.). 46, 290.

Tuberculosis Chemotherapy Centre, Madras (1964). Bull. Wld Hlth Org. 31, 247.

\section{Participation in Meetings of Learned Bodies Overseas}

Lieutenant-General Sir Robert Drew, Director General, Army Medical Services, acted as a Moderator for the Panel on Malaria at the meeting of the Colleges of Physicians held at Boston, Massachusetts, April 1st-5th, 1968. This was a joint venture of the American College of Physicians (49th Annual Session) with the Royal College of Physicians of London, to celebrate its 450th Anniversary.

Colonel W. O'Brien, Professor of Military Medicine at the Royal Army Medical College, presented a paper at the Symposium on Malabsorption and Malnutrition in the Tropics held at Port-au-Prince, Haiti, under the auspices of the Columbia University, Institute of Nutrition Sciences, March 6th-8th, 1968. He also read a paper in Boston, Massachusetts, at the Combined Meeting of the American College of Physicians and the Royal College of Physicians of London, April 1st-5th, 1968.

\section{SENIOR APPOINTMENTS}

The Queen has approved the following appointments:-

Major-General K. F. Stephens, O.B.E., Q.H.S., M.B., F.F.A.R.C.S., Commandant, Royal Army Medical College and Director of Studies, to be Deputy Director of Medical Services, Eastern Command, in May, 1968.

He was born at Taplow, Bucks, on 28th July, 1910, and was educated at Eastbourne College, London University and St. Bartholomew's Hospital.

Brigadier N. G. G. Talbot, O.B.E., T.D., M.D., F.R.C.O.G., to be Commandant, Royal Army Medical College and Director of Studies, in the acting rank of MajorGeneral, in April, 1968.

He was born at Hastings, on 16th February, 1910, and was educated at Great Yarmouth and Reigate Grammar Schools, London University, and King's College Hospital. 